\title{
O trabalho dos pais e o desenvolvimento dos filhos no contexto da pandemia de COVID-19: Um olhar bioecológico
}

\author{
Parents' work and chidren's development in the context of the COVID-19 Pandemic: A \\ bioecological view
}

Trabajo de padres y desarrollo infantil en el contexto de la pandemia COVID-19: Una visión bioecológica

Recebido: 26/07/2021 | Revisado: 30/07/2021 | Aceito: 02/08/2021 | Publicado: 06/08/2021

\author{
Maria de Fátima Góes da Costa \\ ORCID: https://orcid.org/0000-0001-6983-2997 \\ Universidade Federal do Pará, Brasil \\ E-mail: fatimacgoes@gmail.com \\ Lília Ieda Chaves Cavalcante \\ ORCID: https://orcid.org/0000-0003-3154-0651 \\ Universidade Federal do Pará, Brasil \\ E-mail:liliaccavalcante@gmail.com \\ Elson Ferreira Costa \\ ORCID: https://orcid.org/0000-0003-4115-9029 \\ Universidade Federal do Pará, Brasil \\ E-mail: elsonfcosta@gmail.com
}

\begin{abstract}
Resumo
O Modelo Bioecológico do Desenvolvimento Humano de Bronfenbrenner considera que o desenvolvimento é um fonômeno situado no contexto e que assim deve ser estudado. Desse ponto de vista, o ambiente ecológico do desenvolvimento é concebido como uma série de estruturas concêntricas assim denominadas: microssistema, mesossistema, exossistema e macrossistema. Assume-se que o trabalho dos pais é um exossistema que influencia o desenvolvimento infantil na relação com os demais. Com a pandemia de COVID-19, notam-se mudanças no ambiente ecológico da criança formado por seu microsistema familiar e o exosistema constituído pelo trabalho dos pais. O presente estudo tem como objetivo discutir as mudanças trazidas pela Pandemia de COVID -19 para esse exosssitema e suas possíveis repercussões no desenvolvimento infantil. Trata-se de uma pesquisa bibliográfica do tipo revisão narrativa, com caráter descritivo e esploratório e abordagem qualitativa. Para abordagem do tema é apresentada a Teoria Bioecológica de Urie Bronfenbrenner e discutido o trabalho dos pais como um importante sistema ecológico e suas implicações para o desenvolvimento infantil, considerando-se, em particular, as mudanças observadas nesse exossistema a partir da pandemia de COVID-19. De acordo com os achados da pesquisa, é possível afirmar que a bioecologia do desenvolvimento das crianças tem sido afetada por alterações nesse exossistema particular e suas interações com as demais dimensões contextuais (macrossistêmicas e microssistêmicas), interferindo nas atividades, relações e papeis de cada ambiente ecológico que a constituem. As repercussões podem ter efeitos no desenvolvimento infantil os mais diversos, positivos e/ou negativos, sendo necessário investigá-los em curto ou por longo prazo.
\end{abstract}

Palavras-chave: Trabalho dos pais; Desenvolvimento infantil; COVID-19.

\begin{abstract}
Bronfebrenner's Bioecological Model of Human Development considers that development is a phonomen situated in context and that it should be studied as such. From this point of view, the ecological environment of the development is conceived as a series of concentric structures called: microsystem, mesosystem, exosystem and macrosystem. It is assumed that the work of parents is an exosystem that influences child develepment in relation to others. With the COVID-19 pandemic, changes are noted in the child's ecological environment formed by his family microsystem and the exosystem constituted by the parents ${ }^{\prime}$ work. This study aims to discuss the changes brought by the COVID-19 Pandemic to this exossytem and its possible repercussions on child development. This is a literature review of the narrative, review type, with descriptive and exploratory character and a qualitative approach. To approach the topic, the Bioecological Theory of Urie Bronfenbrenner is presented and the work of parents is discussed as an important ecological system and is implications for child develepment, considering, in particular, the changes observed in this exosystem after the COVID-19 Pandemic. According to the research findings, it is possible to state that the
\end{abstract}


developmental bioecology of children has been affected by changes in this particular exosystem and its interactions with other contextual dimensions (macrosystemic and microsystemic), intergfering in the activities, relathionships and roles of each ecological environment that constitute it. The repercussions can have the most diverse effects on child development, positive and/or negative, and it is necessary to investigate them in the short or long term.

Keywords: Parents' work; Child development; COVID-19.

\section{Resumen}

El Modelo Bioecológico de Desarrollo Humano considera que el desarrollo es un fonómeno situado en contexto y que debe ser estudiado como tal. Desde este punto de vista, el entorno ecológico se concibe como una serie de estructuras concéntricas de nominadas microsistema, mesosistema, exosistema y macrosistema. Se asume que el trabajo de los padres se considera un exosistema que influye en el desarrollo del niño en ralación con los demás. Con la pandemia de COVID-19, se notan cambios en el entorno ecológicos del niño formado por su microsistema familiar y el exosistema constituido por el trabajo de los padres. Este estudio tiene como objetivo discutir los cambios que trajo la Pandemia COVID-19 a este exosistema y sus posibles repercusiones en el desarrollo infantil. Se trata de una revisión de la literatura del tipo revisión narrativa, con carácter descriptivo y exploratorio y un enfoque cualitativo. Para abordar el tema, se presenta la Teoría Bioecológica de Urie Bronfenbrenner y se discute el trabajo de los padres como un sistema acológico importante y sus implicaciones para el desarrollo infantil, considerando, en particular, los cambios observados en este exosistema luego de la pandemia de COVID-19. Según los resultados de la investigación, es posible afirmar que la bioecología del desarrollo de los niños se ha visto afectada por cambios en este exosistema en particular y sus interacciones con otras dimensiones contextuales (macrosistémica y microsistémica), interfiriendo en las actividades, relaciones y roles de cada ambiente ecológico que lo constituye. Las repercusiones pueden tener los más diversos efectos sobre el desarrollo infantil, positivos y/o negativos, y es necesario investigarlos a corto o largo plazo.

Palabras clave: Trabajo de los padres; Desarrollo infantil; COVID-19.

\section{Introdução}

O Modelo Bioecológico do Desenvolvimento Humano de Bronfenbrenner (2005/2011) considera o desenvolvimento humano como sendo um fonômeno situado no contexto e que assim deve ser estudado. Para Bronfenbrenner (1996), o ambiente ecológico é concebido como uma série de estruturas concêntricas denominadas microssistema, mesossistema, exossistema e macrossistema. Estes contextos de desenvolvimento possuem interconexão e influência entre si, tendo conseqüências no modo como os pais agem com seus filhos e interferem na forma de promoção do desenvolvimento infantil.

Nesse sentido, assume-se que o trabalho dos pais é considerado um exossistema que influencia o desenvolvimento infantil. Pressupõe-se, ainda, que quaisquer alterações neste microssistema influenciam o desenvolvimento infantil, assim como, quaisquer mudanças no exossistema trabalho dos pais interferirá no microambiente familiar e consequentemente no desenvolvimento infantil.

Nos dias atuais, com a pandemia de COVID-19, foram adotadas medidas de isolamento social para conter a disseminação da doença, sendo observadas, em decorrência disso, mudanças nos ambientes ecológicos da criança formados por seu microsistema familiar e o exosistema associado ao trabalho dos pais. Dessa forma, o presente estudo tem como objetivo discutir as mudanças trazidas pela Pandemia de COVID -19 para o exosssitema constituído pelo trabalho dos pais e suas possíveis repercussões no desenvolvimento infantil.

\section{Metodologia}

O presente trabalho trata-se de uma pesquisa bibliográfica do tipo revisão narrativa, descritiva e esploratória com abordagem qualitativa. Segundo Lakatus e Marconi (2003) a pesquisa bibliográfica permite levantamento de referências e acesso a conteúdos relacionado a determinado tópico. A revisão narrativa permite descrever e discutir o tópico estudado em uma perspectiva contextual ou teórica (Rother, 2007).

O caráter exploratório-descritivo, conforme Pereira et al., (2018), refere-se à pesquisa que tem como ambiente natural levantamento bibliográfico, com análise minuciosa e descritiva do objeto de estudo. Para este estudo foi realizada busca 
bibliográfica em plataformas de pesquisas científicas como: Google Acadêmico, Portal de Periódicos da Capes, periódicos de revistas científicas e repositórios de universidades. Foram utilizadas as seguintes palavras chaves: Trabalho dos pais, Teoria bioecológica, Exossistema, Desenvolvimento infantil, COVID-19.

\section{Resultados e discussão}

\section{A Teoria Bioecológica}

A Teoria Bioecológica do Desenvolvimento Humano de Bronfenbrenner (2005/2011) parte da premissa de que o desenvolvimento humano é um fenômeno 'situado- no-contexto', e assim deve ser estudado. Essa teoria é constituída por quatro núcleos dinâmicos e interdependentes, cada um deles representando um recurso a ser utilizado para investigar o desenvolvimento humano: o Processo, a Pessoa, o Contexto e o Tempo (PPCT).

Ao Processo, primeiro núcleo do modelo PPCT, Bronfenbrenner (2005/2011) atribui valor imprescindível ao desenvolvimento infantil. É definido como as trocas estabelecidas entre o ser em desenvolvimento e o ambiente externo imediato: pessoa, objetos e símbolos. Exige participação ativa em interação progressivamente mais complexa e recíproca, devendo acontecer em uma base bastante regular durante longos períodos de tempo.

De acordo com o conceito adotado por Bronfenbrenner (2005/2011), os processos proximais se realizam em atividades solitárias, de interação da pessoa em desenvolvimento com objeto ou símbolo do meio, como por exemplo, a criança solitariamente com um livro de histórias; ou em atividades do sujeito em desenvolvimento com outras pessoas. Neste caso, tem-se a formação do sistema diádico (dois sujeitos: pai-filho, mãe-filho), do sistema triádico (três pessoas em interação: paimãe-filho) e, por último, poliádico (quatro ou mais sujeitos: pai-mãe-irmão-filho).

As díades, no contexto familiar, em especial, pais-filhos, são fundamentais ao desenvolvimento infantil, tendo em vista que, por si só, são contextos críticos para o desenvolvimento, servindo como "blocos construtores" no microssistema familiar, a partir dos quais formar-se-ão outras estruturas interpessoais mais complexas, como as tríades e as tétrades com a inclusão dos demais membros.

Como segundo núcleo do Modelo PPCT estão as características pessoais de ambos os envolvidos no processo de desenvolvimento: no contexto familiar, sejam pais- filhos, adultos- crianças. Essas características sejam sócio emocionais, motivacionais ou cognitivas, conforme Bronfenbrenner e Morris (2006), podem direcionar o curso dos processos proximais, dada a capacidade de afetar o sentido (direção) e o poder deles, sendo que, ao mesmo tempo, tais características podem ser concebidas como produtos da própria dinâmica desenvolvimental. Os autores consideram que podem ativar ou retardar a ocorrência dos processos proximais, influenciando no processo de desenvolvimento infantil três domínios referentes às características pessoais: disposições (características desenvolvimentais generativas, que são positivas, e características desenvolvimentais disruptivas, que dificultam os processos proximais); recursos (referem-se aos elementos para o funcionamento efetivo do processo proximal nos estágios de desenvolvimento, como por exemplo, deficiências e habilidades psicológicas) e demandas pessoais (características sobre a capacidade de encorajar ou desencorajar reações do meio ambiente social que podem prejudicar ou favorecer os processos proximais e o crescimento psicológico, como a personalidade e a aparência).

O núcleo contexto caracteriza-se por qualquer acontecimento ou condição que pode influenciar ou ser influenciado pelo indivíduo em desenvolvimento (Bronfenbrenner, 2005/2011). Nesse sentido, tanto o contexto, quanto o indivíduo, estabelecem uma relação de influência mútua. Engloba a concepção de ambiente ecológico, ou seja, funciona como um sistema organizado que sustenta o desenvolvimento. Para Bronfenbrenner (1996), o ambiente ecológico é concebido como uma série de estruturas encaixadas, uma dentro da outra. Essas estruturas são chamadas de microssistema, mesossistema, exossistema e 
macrossistema.

Por microssistema, entende-se o contexto mais imediato de vida do ser em desenvolvimento, onde ocorrerão as atividades, papéis e relações interpessoais com características físicas, sociais, simbólicas capazes não apenas estimular, mas também inibir o envolvimento nas interações humanas (Bronfenbrenner, 1996/2011). Como exemplo de microssistema, destaca-se a família, como o contexto primário do desenvolvimento, na qual serão estabelecidos padrões de interação com o desempenho de atividades específicas a partir de papéis determinados (Bronfenbrenner, 2011).

Englobando o microssistema, está o mesossistema, concebido como um sistema de microssistema, por conter as interrelações entre dois ou mais ambientes em que o sujeito em desenvolvimento participa de forma ativa e frequente. Um exemplo de mesossistema seriam as relações entre dois distintos microssistemas, família e escola (Bronfenbrenner, 1996).

Adicionalmente, o exossistema se refere a um ou mais ambientes nos quais o sujeito em desenvolvimento não está inserido como um participante ativo. Entretanto, nele, ocorrem eventos que influenciam o seu desenvolvimento. Como exemplo de exossistema, tem-se o local de trabalho dos pais, influenciando sobre o comportamento e o desenvolvimento do sujeito. Os pais de uma criança podem vivenciar conflitos no trabalho, desencadeando fatores estressantes, e como resultado eles podem se sentir menos capazes de prestar cuidados de qualidade à criança (Bronfenbrenner, 2011).

O macrossistema é definido como um "padrão global de ideologia e organização das instituições sociais comuns em uma determinada cultura ou subcultura" (Bronfenbrenner, 2011, p.115), ou seja, engloba características dos outros sistemas e os valores de cultura e subcultura, crenças, ideologias, sistema socioeconômico, sistema jurídico, entre outros. As questões dos cuidados parentais vivenciados e transmitidos pela cultura comum na estrutura da entidade familiar, a própria valorização e função dos papeis parentais para determinada sociedade; podem ser utilizados como exemplos desse subsistema (Vasconcelos, 2011).

Considerando a Teoria da Bioecologia do Desenvolvimento Humano, os contextos de desenvolvimento possuem interconexão e influência entre si, tendo conseqüências no modo como os pais agem com seus filhos e interferem na forma de promoção do desenvolvimento infantil. Segundo Bronfenbrenner (1996), o crescimento psicológico da criança é afetado pela ação mútua entre os ambientes mais importantes dos quais ela faz parte e convive com adultos e outras crianças, tais como, a família, a creche, a escola. Do mesmo modo, a criança é influenciada pelo que acontece nos ambientes frequentados pelos pais (o seu local de trabalho, por exemplo) e pelas mudanças e/ou continuidades ao longo do tempo nesses ambientes, sendo esse efeito cumulativo.

Considerando-se a perspectiva do modelo PPCT, a dimensão tempo permite verificar a influência no desenvolvimento infantil das mudanças que ocorrem ao longo do ciclo de vida tanto individual como familiar. Segundo Bronfenbrenner e Morris (2006), existem três níveis de análise do tempo. O primeiro é denominado microtempo, caracterizado pela continuação ou descontinuação dos episódios dos processos proximais. Com por exemplo, o tempo de duração dasinterações pai- filho e mãefilho e pai-mãe-filho. O mesotempo, que diz respeito à periodicidade, frequência ou regularidade dos processos proximais no curso de intervalos de tempos maiores como dias, semanas. Por último, o macrotempo faz referência aos eventos mutáveis dentro da sociedade, ou mesmo dentro do desenvolvimento da criança, bem como dos eventos ocorridos através de gerações.

Na perspectiva da Teoria Bioecológica do Desenvolvimento e dos núcleos do Modelo PPCT, a família é um microssistema, ambiente primário e abrangente, que mantém relações de mútua influência com as demais dimensões ecológicas e seus efeitos para o desenvolvimento. Pressupõe-se, assim, que quaisquer alterações neste microssistema influenciam o desenvolvimento infantil, assim como, quaisquer mudanças no exossistema trabalho dos pais interferirá no microambiente familiar e consequentemente no desenvolvimento infantil. Do mesmo modo, os acontecimentos do microssistema familiar podem influenciar no exossistema trabalho dos pais, trazendo repercussões para o desenvolvimento infantil. 


\section{O trabalho dos pais como exossistema e suas implicações para o desenvolvimento infantil}

O desenvolvimento infantil está relacionado diretamente ao processo de funcionamento familiar, ambos de forma bidirecional e recíproca, em um processo ativo de transformação e crescimento, no qual a criança não é considerada apenas como um elemento sobre o qual o meio ambiente gera o seu impacto, mas como um ser em crescimento e dinâmico. Assim, a criança, como pessoa desenvolvente, progressivamente se insere e o reestrutura, seja este um ambiente com relações próximas ou distais, estando expostas aos efeitos dos contextos em que está inserida, considerando-se o microssistema familiar e os exosssitemas que o circundam, entre eles, o trabalho dos pais.

Para Bronfenbrenner (2011), os dois contextos, família e trabalho, reúnem as atividades, papéis e relações, que levam as formações de processos proximais, imprescindíveis para a sobrevivência humana, voltadas à provisão material e afetiva. Em 1996, o autor já constatava alterações no microssistema familiar com repercussão negativa no desenvolvimento infantil. Entre elas, o crescimento sociodemográfico de famílias monoparentais, neste caso, a maioria chefiada por mulheres, com elas sendo o único genitor responsável pelas crianças, tanto materialmente quanto emocionalmente. Ao sair para trabalhar, há ausência do único cuidador engajado para suprir as necessidades de cuidado das crianças: nos afazeres, no estímulo à educação, no acompanhamento escolar e emocional, na transmissão de valores e limites (Vasconcelos, 2011; Medeiros, Aguiar \& Barham, 2017).

Outra questão levantada por Bronfenbrenner (1999) refere-se às alterações havidas no contexto familiar com efeitos deletérios para o desenvolvimento infantil, influenciadas por características exossistêmicas como longas jornadas de trabalho. Deste modo, observa-sea existência de um conjunto de situações que têm dificultado o engajamento e a participação dos pais nas atividades, papéis e relações que envolvem os cuidados diários e a educação dos seus filhos. Estudos de Feijó, Júnior e Nascimento (2017), Mendonça e Matos (2015), Vilela e Lourenço (2017), Medeiros, Aguiar e Barham (2017), Bandeira, Ferreira e Cabral (2019) sugerem que as mudanças no mercado de trabalho, muitas vezes, com os dois cônjuges trabalhando, as redefinições de papéis familiares e a dificuldade de conciliar o tempo entre as duas esferas, seriam os principais causadores de conflito.

Diante disso, com base em Bronfenbrenner (1979), assume-se que, tanto o pai quanto a mãe, membros de famílias monoparentais ou biparentais, buscam satisfazer as necessidades financeiras familiares, engajando-se, cada vez mais, no mundo do trabalho, como forma de sobrevivência; por outro lado, em razão disso, a criação dos filhos pode estar sendo prejudicada. Sendo assim, aponta-se para um conflito entre o trabalho e a qualidade no cuidado/educação/proteção dos filhos. $\mathrm{O}$ autor reitera que nós opusemos as duas, quando, na verdade, elas deveriam ser vistas como complementares.

Segundo Vasconcelos (2011), o exercício da função parental é dificultada, senão impedida, por outras variáveis como o aumento da jornada de trabalho e a diminuição do tempo livre. Por conta das condições de trabalho,o trabalhador pode não conseguir investir tempo, de forma regular, na convivência com o filho, interagindo em díades de atividades conjuntas, comprometendo os processos proximais, que proporcionem à criança o desenvolvimento de suas habilidades, aquisição de conhecimentos e valores.

Além disso, as longas jornadas de trabalho podem interferir no estabelecimento de uma rotina regular e constante de acordo com as necessidades psicológico-emocionais, de aprendizado, de sociabilização da criança e do adolescente, pois os pais são impedidos pelas longas jornadas de trabalho, a multiplicação delas, as jornadas imprevisíveis, o mosaico de horários de trabalhos flexíveis, o trabalho em domicílio, o qual coloca o trabalhador 24 horas por dia à disposição do empregador (Aguiar, Bastos, Jesus \& Lago, 2014; Feijó, Júnior \& Nascimento, 2017).

Em 1979, Bronfenbrenner já criticava a imposição de jornadas prolongadas, exaustivas e estressantes ao trabalhador que obrigam a família e os filhos a conviverem com a ausência de um ou do único cuidador, ressaltando-se que há a possibilidade de que esse possa estar fisicamente presente, mas não estar disponível à família e aos filhos, pois pode necessitar 
compensar com sono o que foi despendido durante a jornada de trabalho, necessitar buscar qualificação em ambiente externo ao da casa ou trabalhar no próprio microssistema da família, comprometendo o tempo e a qualidade dos processos proximais. Em resumo, enfatiza que os pais não poderiam criar seus filhos apenas em seu tempo livre, longe do trabalho.

Nessa direção, Vasconcelos (2011) refere outros elementos característicos dessa fronteira exossistêmica que geram instabilidade e estresse nas relações familiares, resultando em mudanças na sua estrutura, a exemplo daquelas ocasionadas por separação ou divórcio e recasamentos a partir de crises conjugais.

Outra variável exossistêmica que tem sido investigada em pesquisas é o estresse no trabalho e sua relação no microssistema (relação pai-criança, relação conjugal), o que inclui vários aspectos da convivência social, bem como, os efeitos deste sobre a tensão observada comumente nas relações conjugais (Braun, Vurheller \& Oliveira, 2016; Feijó, Júnior \& Nascimento, 2017; Mendonça \& Matos, 2015). Portanto, qualquer impacto que os estressores de trabalho têm sobre a díade conjugal também pode ser repercutido na díade pai-criança (Bronfenbrenner, 1986).

Uma vez mais essas preocupações remetem às contribuições deixadas por Bronfrenbrenner (1999) sobre a questão. Para ele, em decorrência da "ausência dos pais", por conta das demandas e exigências cada vez maiores do mundo do trabalho, as crianças estariam sendo influenciadas pelas mídias (TV, filmes, vídeo games, CDs e Internet), enfatizando o mercantilismo, a sexualidade, o abuso de substâncias entorpecentes e a violência, resultando na ausência de modelos adultos positivos para internalizar as normas de comportamento. Por sua vez, Vasconcelos (2011) considera que o impacto psicológico e social midiático provocado ao desenvolvimento infantil pode ser observado em todos os aspectos do ser humano, desde sua construção psicológica até seus valores e referências de comportamento.

Segundo Bronfenbrenner (2011), alguns pais podem criar estratégias de superação e enfrentamento das múltiplas demandas sobre seu tempo e energia, entretanto o inverso também pode ocorrer. Para ele, os pais que trabalham, muitas vezes, são sobrecarregados por terem que responderàs demandas apresentadas por outras pessoas, se sentindo influenciados por pressões sociais e econômicas sobre as quais não possuem qualquer controle. Eles não escolhema dedicação ao trabalho em detrimento das funções parentais e do exercício da parentalidade, mas buscam sobreviver ao conflito entre as duas. Evidências sugerem que as crianças sofrem as repercussões dessas complexas relações.

Hipotetiza-se, assim, que o mundo do trabalho pode contribuir para prejudicar a efetividade dos processos proximais que envolvem pais e filhos no ambiente familiar, fazendo com que este se torne instável e estressor, atingindo diretamente a relação conjugal e repercutindo na relação pai-filho. Nesse sentido, entende-se serem possivelmente múltiplas as determinações e as manifestações da influência do exossistema mundo do trabalho sobre o microssistemada vida infantil, e assim devem ser compreendidas na atualidade.

\section{As mudanças no exossistema trabalho dos pais relacionadas à pandemia de COVID - 19 e suas repercussões para o desenvolvimento infantil}

Frente a pandemia de COVID -19 (do inglês Coronavirus Disease 2019), causada pelo Novo Coronavírus da Sindrome Respiratória Aguda Grave 2 (SARS-COV-2 do inglês Severe Acute Respiratory Syndrome Coronavirus 2), colocouse como necessidade e estratégia de maior eficácia a aplicação de medidas de isolamento social para conter o avanço da doença e salvar vidas (Corrêa, Nacimento \& Omura 2020; Anderson et al., 2020).

A determinação do distanciamento social resultou em mudanças e desafios para as famílias, entre eles: a convivência por período prolongado; alteração da rotina de frequentar escolas, creches, núcleos assistenciais, esporte e lazer; implantação de modalidade de trabalho realizado à distância pelos pais; mudanças no ambiente físico para reorganizar demandas de trabalho, escola e lazer; sobrecarga de trabalho doméstico; instabilidade no emprego, surgimento de desemprego e problemas financeiros; ausência ou diminuição de assistência da rede de saúde e assistência social e comunitária à família, conflitos 
familiares, entre outros (Linhares \& Enumo 2020).

Creches e escolas foram fechadas e as medidas de distanciamento social, levaram às famílias à restrigir o contato de crianças com outras pessoas mesmo da família, como os avós, promovendo limitações alternativas de cuidados formal ou parental (Yerks et al., 2020). Segundo Cruz, Cavalcante, Costa e Pinheiro (2021) as crianças tem sido lembradas pelos efeitos disruptivos dessas medidas, de mudanças nas condições de trabalho dos pais e/ou dos principais cuidadores, que tem promovido privação da convivência familiar e comunitária, do acesso à educação e saúde.

Entre outros autores, Benner e Mistry (2020) apontam como fatores de riscos para o desenvolvimento, durante a pandemia, o estresse e as incertezas que acompanham a pandemia, como alterações no trabalho dos pais e nas circunstâncias econômicas, a diminuição do acesso a creches e escolas, mudanças abruptas da modalidade de ensino presencial para aprendizagem online. Concluem, assim, que a vida de muitas famílias foi gravemente afetada. Os pais e cuidadores que trabalham estão tentando conciliar a demanda do trabalho remoto, com os cuidados infantis, incluindo a assistência às crianças que estão em aulas online. Os trabalhadores em atividades consideradas essenciais estão enfrentando as demandas dos cuidados infantis, e as preocupações com a saúde e segurança. Além disso, tem as famílias que enfrentam na pandemia a perda de emprego e insuficiência financeira.

A Organização Internacional do Trabalho divulgou monitoramento sobre a situação da ocupação diante da pandemia, estimando que 1,6 bilhão de trabalhores informais estão ameaçados pelo aumento da pobreza (Eurofound, 2020). Segundo o DIEESE (2020), no Brasil, os impactos da COVID -19 têm sido terríveis sobre a economia, com repercussões sociais imprevisíveis. A Pesquisa Nacional por Amostra de Domicílios (PNAD) - COVID -19 do IBGE, revela que entre oito e nove milhões de trabalhadores passaram a trabalhar na modalidade do teletrabalho (remoto/home office) em suas residências, sendo em julho de 2020, em torno de $10 \%$ da população ocupada (Bridi, 2020).

$\mathrm{O}$ trabalho remoto/home office é predominantemente realizado de forma virtual, com uso de computadores, wabcams, plataformas digitais, entre outras. Esta modalidade de trabalho, portanto, revela-se como um novo indicador de desigualdade econômica no país, além de o perfil dos trabalhadores e de ocupação ser altamente escolarizado (Bridi, 2020). Além das mudanças econômicas, esse cenário tem causado muitas outras no microsssistema familiar em todo o mundo, especialmente em relação às ocupações presentes no cotidiano, já que a maioria das pessoas agora passa mais tempo em casa. Segundo Corrêa, Nascimento e Omura (2020), a expressão "Fica em casa" conduz as pessoas ao ambiente onde ocorre a maioria das ocupações que fazem parte do seu dia-a-dia. Ou seja, nos moldes em que discutiu Bronfenbrenner (2005/2011), é possível dizer que ocorre como que a sobreposição de distintos ambientes ecológicos, envolvendo, contudo, uma conjunção de papéis, atividades e relações antes em diferentes contextos, ao mesmo tempo e no mesmo espaço.

Outrossim, para Benner e Mistry (2020), praticamente todas as familias estão de algum modo expostas ao estresse relacionado aos fatores econômicos e específicos da pandemia , como o confinamento e mudança na rotina. Essas experiências levam os pais à sobrecarga emocional, limitando o uso de recursos psicológicos necessários para atender as demandas emocionais e cognitivas das crianças e aumentam o uso de práticas parentais mais duras e menos responsivas. Por exemplo, o microssistema escolar fez sua inscrição no microssistema familiar. Além disso, passou-se a existir um ambiente, ainda não mencionado por Bronfenbrenner, descrito hoje como ambiente virtual, no qual os indivíduos conseguem interagir ainda que remotamemte, em plataformas digitais, com troca de influências entre si.

A pandemia trouxe a necessidade de se ajustar a uma nova rotina, acúmulo de trabalho e funções e os temores de um cenário econômico incerto, além do medo de adoecer, preocupações com a própria saúde e de seus amigos e familiares, provocando sobrecarga e esgotamento. Nesse cenário, mães e pais estão precisando lidar com outras responsabilidades: homeschooling dos filhos, segurança das crianças, gerenciamento do tempo para as demandas do trabalho, dificuldade em lidar com comportamento das crianças, ser produtivo enquanto cuida da casa e inúmeras outras demandas (GPTW, 2020). 
A sobrecarga emocional é clara. A Bonnier Custom Insights perguntou a 500 mães americanas como tem sido trabalhar com os filhos em casa na pandemia: 81\% disseram que a COVID -19 impactou negativamente a produtividade no trabalho; 55\% disseram que o estresse e a ansiedade provocados pelo momento atual impedem o engajamento no trabalho (GPTW, 2020). Segundo Carlson, Petts e Pepin (2020), a pandemia de COVID -19 modificou o trabalho dos pais e a vida familiar. Seu estudo buscou discutir as principais explicações teóricas das divisões de casais e trabalhos domésticos, utilizando dados de 1.025 pais americanos. A análise mostra aumento geral nas responsabilidades domésticas para as mães e aumento na contribuição dos pais. Revela ainda aumento do tempo dos pais gastos com os cuidados com filhos e tarefas domésticas. Mães e pais relatam uma mudança geral para divisões mais igualitárias do trabalho doméstico. Os resultados indicam como relevante para as mudanças: o aumento do tempo em casa, em decorrência de desemprego, teletrabalho e redução do horário de trabalho.

Por outro lado, estudo inicial da Eurofound (2020) sugere que os trabalhadores estão sacrificando o tempo de lazer para atender às demandas de trabalho durante a pandemia. Os resultados da pesquisa revelam que 18\% dos trabalhadores, realizam trabalho em seu tempo livre. Mais de um em cada 4 trabalhadores (27\%) que trabalham em casa como resultado da pandemia, trabalham nas horas vagas para atender às demandas do trabalho. Consequentemente, pessoas com tempo de lazer diminuído experimentam uma pior qualidade de vida, assim como um aumento do risco à saúde e bem estar. Em resumo, a pandemia de COVID -19 alterou todos os aspectos das vidas de crianças, adolescentes e adultos, apresentando riscos significativos para sua saúde e bem-estar. Sua escala e alcance são sem precedentes e a confluência de aspectos econômicos, de saúde e interrupções educacionais que emanam dela terão longa duração e efeitos no desenvolvimento de crianças e jovens (Benner \& Mistry, 2020).

Em razão disso, nos termos estabelecidos pela Teoria Bioecológica, a Pandemia de COVID -19 pode ser definida como um processo macrossistêmico que tem causado alterações no microsssitema familiar e no exossistema trabalho dos pais, interferindo nas atividades, papéis e relações de cada um desses ambientes ecológicos e na interação entre eles Essas mudanças em curso trazem repercussões para o desenvolvimento infantil, positivas e/ou negativas, em curto ou longo prazos.

Quando Bronfenbrenner formulou e divulgou a Teoria Bioecológica do Desenvolvimento Humano, mas sobretudo o Modelo PPCT, considerou os elementos da sociedade existentes à época e suas possíveis variações em razão de fatores que envolviam as configurações familiares, os locais de trabalho, enfim, o contexto histórico que se apresentava. Desse modo, considera-se que o contexto de Pandemia de COVID -19 é marcado por alterações (ou pela agudização delas) nas microestruturas dos ambientes ecológicos, conforme analisou Bronfenbrenner a partir de outros processos macrossistêmicos. Os exemplos impressos pelo autor para cada microssistema podem não corresponder atualmente. Se pensarmos que o conceito de exossistema que seria o ambiente externo ao qual o indivíduo está inserido, não podemos mais considerar o trabalho dos pais, pelo menos de muitos, mais como sendo exossistema, tendo em vista que este está agora submerso no microambiente familiar, fazendo parte deste microssistema, tornando-se um espaço de fronteira, havendo a interelação constante dos papéis e atividades de cada ambiente ecológico.

Para Benner e Mistry (2020), ao se considerar os efeitos da pandemia no desenvolvimento, deve-se considerar o sincronismo mental e as trajetórias desenvolvimentais. Embora, ainda não se encontrem estudos empíricos sobre os impactos das mudanças causadas pela Pandemia de COVID -19 no desenvolvimento infantil. Ao mesmo tempo, pensa-se como ficam as qualidades dos elementos elencados por Bronfenbrenner como sendo fundamentais ao desenvolvimento infantil, tais como: os processos proximais, formação de díades, tendo em vista que estão ocorrendo mudanças e influências constantes na qualidade das interações humanas. Além disso, as características da pessoa tem sido alteradas, exigindo recursos e demandas diferentes para os novos rearranjos de rotina. Isso altera os diferentes papéis desempenhados pelos indivíduos nos diferentes contextos. A pandemia causou alteração no modo como as pessoas se relacionam, como relações acontecem e bem, como Bronfenbrenner coloca no modelo, a forma sistêmica dos eventos, tem sido assim. 
Na perspsectiva da Teoria Bioecológica, pode-se considerar que há um deslocamento de atividades antes realizadas em diferentes ambientes ecológicos para um único. Assim, por exemplo, pode-se dizer que houve um deslocamento de vários aspectos (ou elementos) do exossistema trabalho para dentro do microssistema familiar. Desse ponto de vista, pode-se dizer que houve uma exposição mais direta da família aos fatores negativos (estressores, ansiogênicos, em alguma medida) associados ao ambiente físico e social do trabalho. Por outro lado, com o trabalho remoto, alguns pais passaram a estar mais presentes no ambiente familiar.

Dessa forma, o trabalho dos pais e as mudanças ocasionadas pela Pandemia de COVID -19 precisam ser pensadas com uma visão bioecológica do desenvolvimento que demonstra a conexão entre o trabalho dos pais e os microssistemas, mesossistemas e macrossistemas da criança como pessoa em desenvolvimento. Considerando que a literatura aponta que as características socioemocionais, motivacionais e cognitivas das pessoas envolvidas no ambiente do microssistema familiar são afetadas pelos valores do exossistema do trabalho dos pais. Vasconcelos (2011) enfatiza que, uma vez prejudicadas essas características, a tendência é que o curso, a direção e o sentido dos processos proximais seja negativamente afetado.

Desse modo, fica evidente que as mudanças impostas pela pandemia, têm alterado características socioemocionais, motivacionais e cognitivas das pessoas, comprometendo negativamente os processos proximais. As incertezas e estresse no microssistema familiar; as reais condições de trabalho dos pais, alteradas pelo contexto; as mudanças no macrossistema, com alterações de normas trabalhistas, trazem repercussões para o mircroambiente familiar e consequentemente para o desenvolvimento infantil.

Não se pode deixar de considerar também a influência do macrossistema nos diferentes contextos de desenvolvimento que é permeado por valores, crenças e tomadas de decisões (Bronfenbrenner, 2011), que na atualidade, segundo Linhares \& Enumo (2020), considerando a pandemia, pensando-se nos níveis governamentais, pode ser constituir em fator de proteção para o desenvolvimento infantil e as famílias ou se tornar um elemento complicador da situação. Quanto maiores forem as divergências nas tomadas de decisões, com diretrizes e orientações que gerem insegurança e conflitos no modo de combate e enfrentamento da pandemia no macrossistema, mais conflitos, caos e estresses serão gerados a nível de microssistema. Deixando evidente o quanto os contextos estão estritamente interligados e influenciando de diferentes modos o desenvolvimento humano.

\section{Considerações Finais}

Pode-se concluir que o trabalho dos pais se constitui em um exosssitema com esperada influência no desenvolvimento infantil, nos moldes em que propõe a Teoria Bioecológica. Desse ponto de vista, a Pandemia de COVID-19 é um processo macrossistêmico com alterações as mais diversas no microsssitema familiar e no exossistema trabalho dos pais, interferindo nas atividades, relações e papéis de cada ambiente ecológico. Tais repercussões têm impacto no desenvolvimento infantil, positivas ou negativas, sendo necessário avaliar seus efeitos em curto ou longo prazo.

Dada a complexidade desse fenômeno, sugere-se a realização de pesquisas que tenham como premissa o modelo bioecológico a fim de que se possa investigar os impactos das mudanças trazidas pela COVID-19 ao microssistema familiar e o exossistema trabalho dos pais na direção do desenvolvimento infantil. Estudos empíricos precisam assumir distintos objetivos: 1) investigar como o trabalho remoto tem tido repercussões positivas ou negativas para o desenvolvimento infantil; 2) averiguar se o contexto pandêmico tem agravado ou não o conflito trabalho-família, e facilitado ou dificultado a criação e manutenção dos processos proximais e formação de díades; 3) compreender como as mudanças trabalhistas têm se refletido no microssistema familiar e consequentemente no desenvolvimento infantil; 4) avaliar variáveis relacionadas ao trabalho dos pais, como por exemplo, o tipo de ocupação, a carga horária, o turno, o nível de estresse e a qualidade de vida no trabalho e 
relacionar suas medidas a escores de testes de avaliação do desenvolvimento dos filhos, para verificar correlações e predições.

\section{Referências}

Aguiar, C. V. N., Bastos, A. V. B., Jesus, E. S. \& Lago, L. N. A. (2014). Um estudo das relações ente conflito trabalho-família, comprometimento organizacional entrincheiramento organizacional. Revista Psicologia: Organizações e Trabalho, 14(3), 283-291.

Anderson, R. M., Heesterbeck, H., Klinkenberg, D., \& Hollingsworth, T. D. (2020). How will country-based mitigation measures influence the course of the COVID-19 epidemic? The Lancet. 395 (10228), 931-934.

Bandeira, E. L., Ferreira, V. C., Cabral, A. C. A. (2019). Conflito trabalho-família: a produção científica internacional e a agenda de pesquisa nacional. Revista eletrônica de administração, 25 (1), 49-82.

Benner, A. P., \&, Mistry, R. S. (2020). Child development during the COVID-19 pandemic through a life course theory lens. Child development perspectives, $14(4), 236-243$

Braun, A.C; Vierheller, B; \& Oliveira, M. Z. (2016). Conflito trabalho-família em executivos: uma revisão sistemática de 2009 a 2014 . Revista brasileira de orientação profissional, 17(1), 19-30.

Bridi, M. A. (2020). A pandemia de COVID-19: crise e deteriorização do mercado de trabalho no Brasil. Estudos Avançados, 34 (100): 141-165.

Bronfenbrenner, U. (1976/1996). A ecologia do desenvolvimento humano: Experiências naturais e planejadas. Tradução, M. A. Verosese. Artes Médicas.

Bronfenbrenner, U. (1986). Ecology of the family as a context for human development: research perspectives. Developmental Psychology, $22, \mathrm{n}^{\circ}$ 6, $723-742$.

Bronfenbrenner, U. (2011). Bioecologia do Desenvolvimento Humano: tornando os seres humanos mais humanos. Artmed.

Bronfenbrenner, U. (1999). Growing Chaos in the Lives of Children Youth and Families: How Can We Turn It Around? <http://parenthood.library.wisc.edu/Bronfenbrenner/Bronfenbrenner>

Bronfenbrenner, U, (1979). On Families and Schools: a conversation witj Urie Bronfenbrenner. <http:// www.ascd.org/ASCD/pdf/journals/ed_lead/el_1979 04_brandt.pdf>

Bronfenbrenner, U; \& Morrris, P. A. (2006). The Bioecological Model of Human Development. In: Damon, W; Lemer, R. M.Hadbook of child psychology: theorical models of human developmental.6(1), 795-812.

Bronfenbrenner, U. (2005). Making human beings himan: bioecological perspectives human development. SAGE Publications.

Carlson, D. L., Petts, R., \& Pepin, J. R. (2020). Changes in parent's domestic labor during the COVID-19 Pandemic.

Corrêa, V.A., Nascimento, C. A. V. \& Omura, K. A. (2020). Isolamento social e ocupações. Rev. Interinst. Bras. Ter. Ocup. 4 (3): 351-369.

Cruz, D. A., Cavalcante, L. I. C., Costa, E. F., \& Pinheiro, K. V. (2021). Institucionalização e isolamento social: reflexões a cerca da saúde mental de crianças e adolescentes. Saúde mental no século XXI indivíduo e coletivo pandêmico, 165-177.

DIEESE. Acordos negociados pelas entidades sindicais paara enfrentar a pandemia do coronavírus - COVID 19. Estudos e pesquisas. <https://www.dieese.org.br/estudosepesquisas/2020/estPesq92AcordosCovidAtualizacao.pdf.>

Eurofound. European Foundation for the Improvement of Living and Working Conditions. Living, working and COVID-19, first findings. Eurofound, 2020<htto://eurofound.link/ef20059>

Feijó, M. R; Júnior, E. G; Nascimento, J. M; \& Nascimento, N. B. (2017). Conflito trabalho-família: um estudo sobre a temática no âmbito brasileiro. Pensando famílias, 21(1), 105-119.

GPTW. Great Place To Work. Apoiando mães e pais que trabalham: um guia para gestores em tempo de pandemia. GPTW, 2020. $<$ https://gptw.com.br/conteudo/downloads/apoiar-maes-e-pais-trabalham/>

IBGE. Instituto Brasileiro de Geografia e Estatística. Pesquisa Nacional por Amostra de Domicílios (PNAD)-COVID-19. IBGE, 2020<http://ibge.gov.br>

Lakatus, E. M. \& Marconi, M. A. (2003). Fundamentos da metodologia científica. (5a ed.), Atlas.

Linhares, M. B. M., \& Enumo, S. R. F. (2020). Reflexões baseadas na psicologia sobre efeitos da pandemia de COVID-19 no desenvolvimento infantil. Estudos de Psicologia, 37, e200089.

Medeiros, T. J., Aguiar, J., \& Barham, E. J. (2017). Entre o conflito e o equilíbrio: ferramentas para analisar a relação trabalho-família. Psicologia Argumento, $35(88), 45-62$.

Mendonça, M; \& Matos, P. M. (2015). Conciliação trabalho-família vivida a dois: um estudo qualitativo com casais com filhos pequenos. Análise Psicológica. 33(3), 317- 334

Pereira, A. S. Et al., (2018). Metodologia da Pesquisa Científica. UFSM.

Rother, E. T. (2007). Revisão sistemática X revisão narrativa. Acta Paulista de Enfermagem, 20 (2), 5-6. 
Research, Society and Development, v. 10, n. 10, e169101018730, 2021

(CC BY 4.0) | ISSN 2525-3409 | DOI: http://dx.doi.org/10.33448/rsd-v10i10.18730

Vasconcelos, F. R. C. (2011). "Papai foi pra roça, mamãe foi trabalhar": o princípio da conciliação trabalho-família como fator de proteção dos direitos da criança e do adolescente. Dissertação de mestrado, Universidade Federal de SantaCatarina, Florianópolis, Brasil.

Vilela, N. G. S., \& Lourenço, M. L. (2017). Conflito trabalho-família, políticas de apoio à família e gênero: um panorama do atual cenário de estudos. Revista eletrônica de administração e turismo, 11 (6), 1377-1393. 